Research Paper

\title{
Risk factors for intraoperative massive transfusion in pediatric liver transplantation: a multivariate analysis
}

\author{
Seok-Joon Jin ${ }^{1}$, Sun-Key Kim ${ }^{1}$, Seong-Soo Choi ${ }^{1}$, Keum Nae Kang ${ }^{2}$, Chang Joon Rhyu ${ }^{2}$, Shin Hwang ${ }^{3}$ \\ Sung-Gyu Lee ${ }^{3}$, Jung-Man Namgoong ${ }^{3 凶}$, Young-Kug Kim ${ }^{1 凶}$ \\ 1. Department of Anesthesiology and Pain Medicine, Asan Medical Center, University of Ulsan College of Medicine, Seoul, Republic of Korea; \\ 2. Department of Anesthesiology and Pain Medicine, National Police Hospital, Seoul, Republic of Korea \\ 3. Department of Surgery, Asan Medical Center, University of Ulsan College of Medicine, Seoul, Republic of Korea.
}

$\triangle$ Corresponding authors: Young-Kug Kim, MD, PhD, Professor, Department of Anesthesiology and Pain Medicine, Asan Medical Center, University of Ulsan College of Medicine, 88 Olympic-ro 43-gil, Songpa-gu, Seoul 05505, Republic of Korea. Tel: +82-2-3010-5976; Fax: +82-2-3010-6790; Email: kyk@amc.seoul.kr; Jung-Man Namgoong, MD, PhD, Assistant Professor, Department of Surgery, Asan Medical Center, University of Ulsan College of Medicine, 88 Olympic-ro 43-gil, Songpa-gu, Seoul, 05505, Republic of Korea. Tel: +82-2-3010-1512; Fax: +82-2-3010-6701; Email: namgoong2940@gmail.com.

(c) Ivyspring International Publisher. This is an open access article distributed under the terms of the Creative Commons Attribution (CC BY-NC) license (https://creativecommons.org/licenses/by-nc/4.0/). See http://ivyspring.com/terms for full terms and conditions.

Received: 2016.09.07; Accepted: 2016.12.21; Published: 2017.02.08

\begin{abstract}
Background: Pediatric liver transplantation (LT) is strongly associated with increased intraoperative blood transfusion requirement and postoperative morbidity and mortality. In the present study, we aimed to assess the risk factors associated with massive transfusion in pediatric LT, and examined the effect of massive transfusion on the postoperative outcomes.

Methods: We enrolled pediatric patients who underwent LT between December 1994 and June 2015. Massive transfusion was defined as the administration of red blood cells $\geq 100 \%$ of the total blood volume during LT. The cases of pediatric LT were assigned to the massive transfusion or no-massive transfusion (administration of red blood cells $<100 \%$ of the total blood volume during LT) group. Univariate and multivariate logistic regression analyses were performed to evaluate the risk factors associated with massive transfusion in pediatric LT. Kaplan-Meier survival analysis, with the log rank test, was used to compare graft and patient survival within 6 months after pediatric LT between the 2 groups.

Results: The total number of LT was $112(45.0 \%)$ and 137 (55.0\%) in the no-massive transfusion and massive transfusion groups, respectively. Multivariate logistic regression analysis indicated that high white blood cell (WBC) count, low platelet count, and cadaveric donors were significant predictive factors of massive transfusion during pediatric LT. The graft failure rate within 6 months in the massive transfusion group tended to be higher than that in the no-massive transfusion group (6.6\% vs. $1.8 \%, P=0.068)$. However, the patient mortality rate within 6 months did not differ significantly between the massive transfusion and no-massive transfusion groups $(7.3 \%$ vs. $7.1 \%, P=$ 0.964).

Conclusion: Massive transfusion during pediatric LT is significantly associated with a high WBC count, low platelet count, and cadaveric donor. This finding can provide a better understanding of perioperative blood transfusion management in pediatric LT recipients.
\end{abstract}

Key words: pediatric liver transplantation, massive transfusion, risk factors.

\section{Introduction}

Liver transplantation (LT) has been introduced as a curative treatment for children with end stage liver disease. Since Starzl performed the first successful pediatric LT in 1967 [1], the advances in the surgical techniques, anesthetic management, and immunosuppressant therapy have led to improvements in the long-term survival rate to $>80 \%$ [2]. Nevertheless, hepatic graft failure may still develop, and often affects patient survival after LT. Death in most cases of pediatric LT occurs within 6 
months of the LT [3]. In addition, massive blood loss and subsequent blood transfusion, which are associated with higher morbidity and mortality, are frequently noted during pediatric LT [4-8]. Liver cirrhosis, associated with a bleeding tendency during LT as a result of a complex hemostatic disorder, is not commonly observed in children. In contrast, biliary atresia, a very common disease requiring pediatric LT, is associated with peritoneal adhesion and recurrent inflammation of the bile tree, as most of these patients have previously undergone hepatoportoenterostomy and experience recurrent cholangitis [9]. Thus, peritoneal adhesion in these patients requires a greater amount of blood products and a longer operation time during intraabdominal surgery [10].

The total blood volume of neonates and children is usually small, and hence, there is a greater possibility of massive transfusion during major operations in pediatric patients. Although major advances have been made in surgical and anesthetic management to reduce the use of blood products during LT, the incidence of large blood loss during LT remains high. As the intraoperative blood transfusion requirement is directly related to poor outcomes [11-13], minimizing and predicting the need for massive transfusion during pediatric LT are important. However, only limited information is available regarding the risk factors for intraoperative massive transfusion in pediatric LT recipients.

In the present study, we aimed to evaluate the risk factors associated with massive transfusion during pediatric LT. Moreover, we examined the effect of massive transfusion on postoperative outcomes, such as graft failure and patient mortality, after pediatric LT.

\section{Materials and Methods}

\section{Patient characteristics}

The institutional review board of Asan Medical Center, Seoul, Republic of Korea approved this study. The medical records from the general ward and intensive care units, as well as data on the operation and anesthesia used, were retrospectively reviewed. We enrolled pediatric patients who underwent LT between December 1994 and June 2015. The exclusion criteria were as follows: incomplete data from medical records, preoperative anticoagulant use, and simultaneous transplantation of another organ. The demographic data, primary diagnosis, donor type, surgical technique for the donor, preoperative laboratory values, and intraoperative variables, as well as the presence of elective/emergent surgery, re-LT, ascites, chronic kidney disease, esophageal varix, fulminant hepatic failure, hepatic encephalopathy, peritonitis, previous abdominal surgery, and portal vein thrombosis were recorded to evaluate the risk factors for intraoperative massive transfusion.

\section{General anesthesia}

After routine monitoring (pulse oximetry, electrocardiography, and non-invasive blood pressure recording), general anesthesia was induced by using an intravenous bolus injection of thiopental sodium (5 $\mathrm{mg} / \mathrm{kg})$, fentanyl $(0.5-1 \mu \mathrm{g} / \mathrm{kg})$, and rocuronium $(0.6$ $\mathrm{mg} / \mathrm{kg})$ or vecuronium $(0.15 \mathrm{mg} / \mathrm{kg})$. After tracheal intubation, anesthesia was maintained using 1-2 vol\% sevoflurane, $50 \%$ oxygen in medical air, a continuous infusion of fentanyl (3-5 $\mu \mathrm{g} / \mathrm{kg} / \mathrm{h})$, and rocuronium $(0.2 \mathrm{mg} / \mathrm{kg} / \mathrm{h})$ or vecuronium $(0.05 \mathrm{mg} / \mathrm{kg} / \mathrm{h})$. Patients were mechanically ventilated at a constant tidal volume of $8-10 \mathrm{ml} / \mathrm{kg}$, and the respiratory rate was adjusted to maintain the end-tidal carbon dioxide partial pressure between 35 and $40 \mathrm{mmHg}$ during the operation. Arterial and central venous catheters were placed for hemodynamic monitoring and blood sampling. Crystalloid (plasma solution A, CJ Pharmaceutical, Seoul, Korea) and colloid (albumin) were administered during LT.

\section{Surgical procedure}

The surgical technique comprised a bilateral subcostal incision, with extension to the xiphoid, or an inverted T-shaped incision. Total hepatectomy was performed in the recipients after clamping the inferior vena cava, portal vein, and hepatic artery; a venous-venous bypass was not adopted. Prior to engraftment, the donor liver was flushed with $1000 \mathrm{ml}$ of Histidine-Tryptophan-Ketoglutarate solution via the portal vein. Venoplasty of the hepatic vein and/or portal vein in the recipient was preceded by the an-hepatic phase, and engraftment was performed with the anastomosis of the hepatic vein, portal vein, and hepatic artery. We routinely checked the vascular perfusion of the liver graft using Doppler sonography after engraftment. Hemostasis was achieved by direct suture ligation or electrocoagulation. A Roux-en-Y hepaticojejunostomy was performed using interrupted sutures.

\section{Definition of massive transfusion}

Since the total blood volume in children varies according to age, the definition of massive transfusion in children should be relative to the total body volume of specific age groups [8]. The total blood volume in children aged $>3$ months was considered to be 70 $\mathrm{ml} / \mathrm{kg}$ [14]. Massive transfusion was defined as the administration of red blood cells $\geq 100 \%$ of the total blood volume. The cases of pediatric LT were 
assigned to the massive transfusion group (administration of red blood cells $\geq 100 \%$ of the total blood volume during LT) or no-massive transfusion group (administration of red blood cells $<100 \%$ of the total blood volume during LT). Intraoperative red blood cell transfusion was performed in cases where the hemoglobin level was $<8.0 \mathrm{mg} / \mathrm{dl}$.

\section{Postoperative outcomes}

The postoperative outcome measures included graft failure and patient mortality. We used the definition of early graft failure reported in previous studies [15-17]. We limited the survival analysis of grafts to 6 months in order to evaluate the influence of massive transfusion on early graft dysfunction and to minimize other factors that may contribute to late graft dysfunction, such as newly developed liver disease. We also defined early patient mortality as death that occurred within 6 months of the surgery.

\section{Statistical analysis}

Data were expressed as means \pm standard deviation or number (\%), as appropriate. Continuous variables were compared using Student's $t$-test or Mann-Whitney U test, whereas categorical variables were compared using the $\chi^{2}$ test or Fisher's exact test, as appropriate. The most relevant risk factors associated with intraoperative massive transfusion were selected in the univariate logistic regression analysis. Variables with a $P$ value $<0.2$ in the univariate logistic regression analysis were included in the final multivariate logistic regression analysis. In all other analyses, except for univariate logistic regression analysis, a $P$ value $<0.05$ was considered statistically significant. Kaplan-Meier survival analysis, with a log rank test, was used to compare graft and patient survival within 6 months of pediatric LT, between the massive transfusion and no-massive transfusion groups. Statistical analyses were conducted using R (version 3.1.2; R Foundation for Statistical Computing, Vienna, Austria), SigmaStat for Windows (version 3.5; Systat Software, Inc., Chicago, IL), and SPSS for Windows (version 23.0.0; IBM Corporation, Chicago, IL).

\section{Results}

Of the 257 pediatric LT procedures conducted during the study period, 249 were included in the analysis (Figure 1). The recipient age ranged from 3 months to 17 years. The total volume of red blood cell transfusion for all patients was $126.7 \pm 175.4 \mathrm{ml} / \mathrm{kg}$. The distribution of the red blood cell transfusion amount is illustrated in Figure 2. Intraoperative massive transfusion was observed in 137 (55.0\%) of 249 LT procedures, whereas 14 (5.6\%) LT procedures did not require blood transfusion (Figure 2).

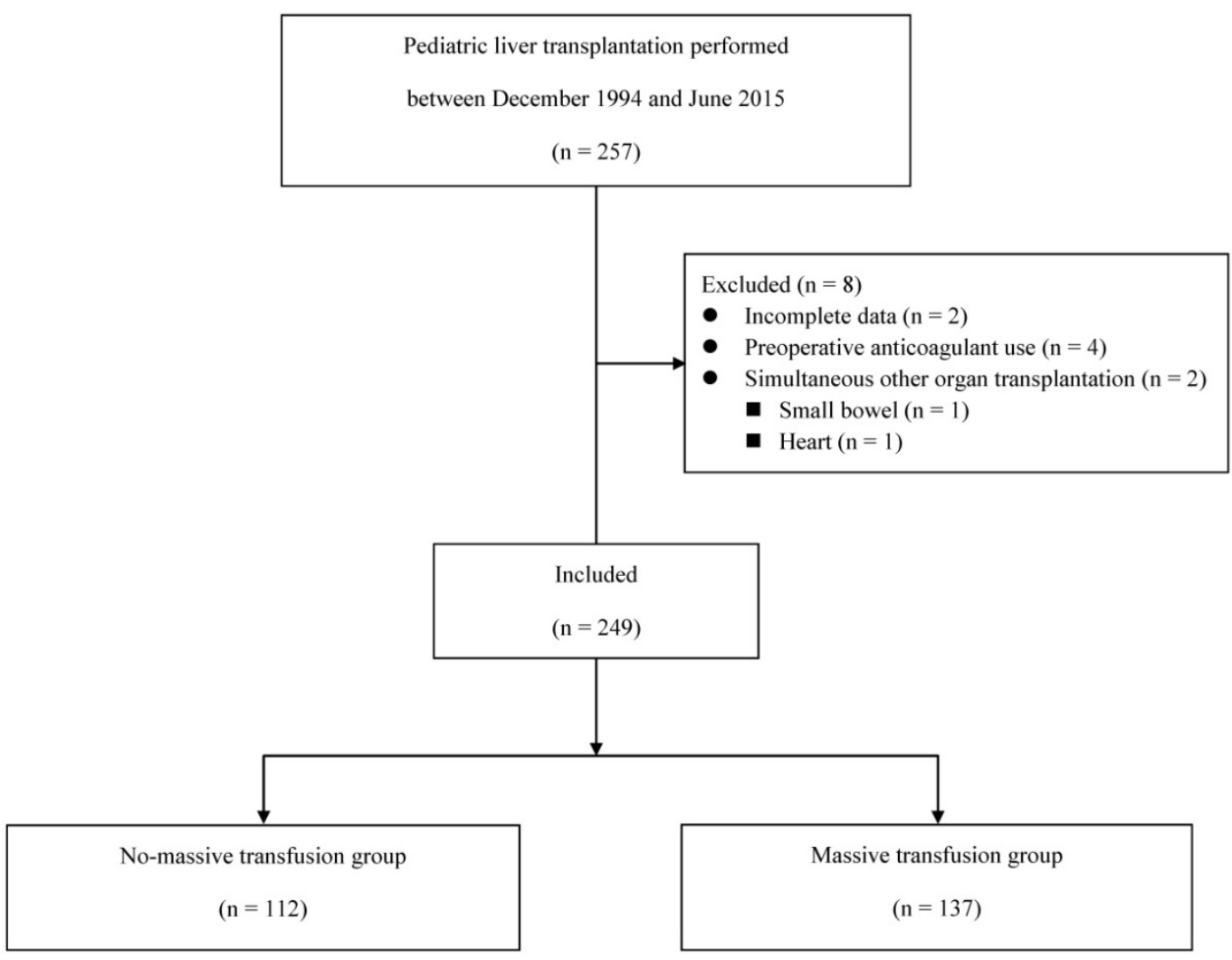

Figure 1. Study flow chart. 


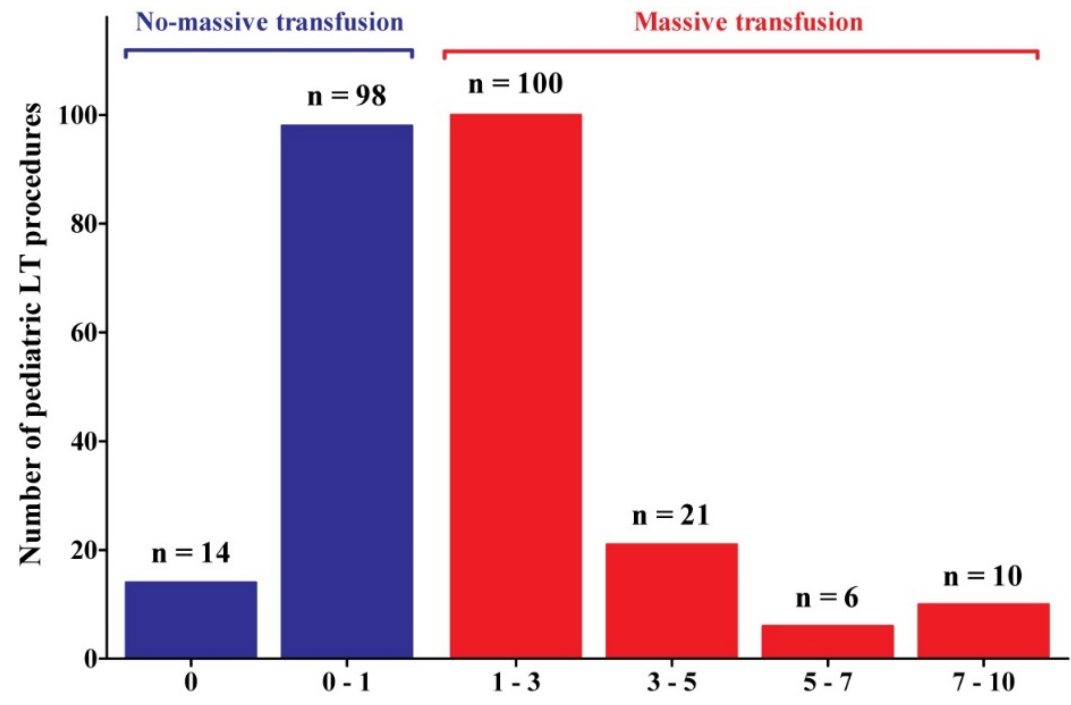

Transfused red blood cell volume/total blood volume

Figure 2. Histogram representing the distribution of the ratio of transfused red blood cell volume to total blood volume. No-massive transfusion (blue bars) indicates the administration of red blood cell $<100 \%$ of the total blood volume during liver transplantation. Massive transfusion (red bars) indicates the administration of red blood cell $\geq 100 \%$ of the total blood volume during liver transplantation. LT, liver transplantation.

Preoperative characteristics were compared between the massive transfusion group and no-massive transfusion group (Table 1). The sex, donor type, and surgical technique for the donor excluding the left lateral segment, as well as the presence of ascites and chronic kidney disease significantly differed between the massive transfusion and no-massive transfusion groups (Table 1). The WBC, hemoglobin, platelet, protein, and C-reactive protein values were also significantly different between the 2 groups (Table 2). A greater amount of cryoprecipitate, fresh frozen plasma, platelet concentrate, crystalloid, and colloid was administered in the massive transfusion group than in the no-massive transfusion group (Table 2).

The results of univariate analysis are summarized in Table 3. Sex, cadaveric donor, and surgical technique for the donor; WBC, hemoglobin, platelet, albumin, and creatinine values; presence of emergent LT, re-LT, ascites, and chronic kidney disease; and operation time were selected for inclusion in the multivariate logistic regression analysis $(P<0.2)$. Multivariate logistic regression analysis indicated that high WBC count, low platelet count, and cadaveric donor were significant predictive risk factors of massive transfusion during pediatric LT (Table 4).

The graft failure rate within 6 months of LT in the massive transfusion group tended to be higher than that in the no-massive transfusion group, although the values did not significantly differ $(6.6 \%$ vs. $1.8 \%, P=0.068$ ) (Figure 3). However, the mortality rate within 6 months of LT did not differ significantly between the massive transfusion and no-massive transfusion groups $(7.3 \%$ vs. $7.1 \%, P=0.964)$ (Figure $3)$.

Table 1. Preoperative characteristics.

\begin{tabular}{|c|c|c|c|}
\hline & $\begin{array}{l}\text { No-massive } \\
\text { transfusion }(\mathrm{n}=112)\end{array}$ & $\begin{array}{l}\text { Massive transfusion } \\
(\mathrm{n}=137)\end{array}$ & $P$ value \\
\hline \multicolumn{4}{|l|}{ Sex } \\
\hline Female/Male & $51(45.5 \%) / 61(54.5 \%)$ & $80(58.4 \%) / 57(41.6 \%)$ & 0.043 \\
\hline Age (years) & $4.7 \pm 4.7$ & $4.1 \pm 5.0$ & 0.337 \\
\hline Weight (kg) & $19.8 \pm 15.5$ & $18.7 \pm 18.3$ & 0.593 \\
\hline Height $(\mathrm{cm})$ & $99.4 \pm 32.0$ & $94.1 \pm 35.1$ & 0.221 \\
\hline Body mass index $\left(\mathrm{kg} / \mathrm{m}^{2}\right)$ & $18.1 \pm 5.6$ & $17.3 \pm 3.0$ & 0.135 \\
\hline \multicolumn{4}{|l|}{ Primary diagnosis } \\
\hline Biliary atresia & $53(47.3 \%)$ & $69(50.4 \%)$ & 0.633 \\
\hline Wilson's disease & $5(4.5 \%)$ & $12(8.8 \%)$ & 0.181 \\
\hline Other diseases ${ }^{a}$ & $54(48.2 \%)$ & $56(40.9 \%)$ & 0.246 \\
\hline \multicolumn{4}{|l|}{ Donor type } \\
\hline Living/Cadaveric donor & $105(93.8 \%) / 7$ (6.3\%) & $\begin{array}{l}111(81.0 \%) / 26 \\
(19.0 \%)\end{array}$ & 0.003 \\
\hline \multicolumn{4}{|l|}{$\begin{array}{l}\text { Surgical technique for } \\
\text { the donor }\end{array}$} \\
\hline Left lateral segment & $37(33.0 \%)$ & $55(40.1 \%)$ & 0.248 \\
\hline Left lobe & $61(54.5 \%)$ & $48(35.0 \%)$ & 0.002 \\
\hline Other techniques ${ }^{\mathrm{b}}$ & $14(12.5 \%)$ & $34(24.8 \%)$ & 0.014 \\
\hline \multicolumn{4}{|l|}{ Elective/Emergent LT } \\
\hline Elective/Emergent & $89(79.5 \%) / 23(20.5 \%)$ & $97(70.8 \%) / 40(29.2 \%)$ & 0.118 \\
\hline Re-LTc & $4(3.6 \%)$ & $13(9.5 \%)$ & 0.066 \\
\hline Ascites & $49(43.8 \%)$ & $78(56.9 \%)$ & 0.038 \\
\hline Chronic kidney disease & $2(1.8 \%)$ & $11(8.0 \%)$ & 0.028 \\
\hline Esophageal varix & $29(25.9 \%)$ & $30(21.9 \%)$ & 0.461 \\
\hline Fulminant hepatic failure & $31(27.7 \%)$ & $29(21.2 \%)$ & 0.232 \\
\hline Hepatic encephalopathy & $23(20.5 \%)$ & $30(21.9 \%)$ & 0.794 \\
\hline Peritonitis & $24(21.4 \%)$ & $34(24.8 \%)$ & 0.529 \\
\hline $\begin{array}{l}\text { Previous abdominal } \\
\text { surgery }\end{array}$ & $52(46.4 \%)$ & $70(51.1 \%)$ & 0.464 \\
\hline Portal vein thrombosis & $8(7.1 \%)$ & $6(4.4 \%)$ & 0.346 \\
\hline
\end{tabular}

Data are the mean \pm standard deviation or number (\%), as appropriate. LT, liver

transplantation. aOther diseases included hepatoblastoma, viral hepatitis, toxic hepatitis, liver cirrhosis, acute liver failure, glycogen storage disease, and metabolic disease. bOther techniques included right lobe, dual left lobe, and whole liver. ${ }^{~}$ Number of re-LT included 14 re-LT, of which the first and second LTs were conducted during study period, as well as

3 re-LT, of which the first LT was not conducted during study period. 
Table 2. Preoperative laboratory values and intraoperative variables.

\begin{tabular}{|c|c|c|c|}
\hline & $\begin{array}{l}\text { No-massive } \\
\text { transfusion } \\
(\mathrm{n}=112)\end{array}$ & $\begin{array}{l}\text { Massive } \\
\text { transfusion } \\
(\mathrm{n}=137)\end{array}$ & $P$ value \\
\hline \multicolumn{4}{|c|}{ Preoperative laboratory values } \\
\hline $\mathrm{WBC}\left(\times 10^{3} / \mu \mathrm{l}\right)$ & $7.1 \pm 3.8$ & $8.8 \pm 5.4$ & 0.005 \\
\hline Hemoglobin (g/dl) & $10.0 \pm 1.9$ & $9.3 \pm 1.9$ & 0.009 \\
\hline Platelet $\left(\times 10^{3} / \mu \mathrm{l}\right)$ & $167.5 \pm 103.6$ & $133.9 \pm 86.9$ & 0.006 \\
\hline Aspartate transaminase $(\mathrm{U} / \mathrm{l})$ & $406.3 \pm 633.6$ & $590.7 \pm 1610.5$ & 0.255 \\
\hline Alanine transaminase $(\mathrm{U} / \mathrm{l})$ & $382.5 \pm 891.2$ & $410.2 \pm 1044.3$ & 0.824 \\
\hline Total bilirubin (mg/dl) & $16.2 \pm 11.4$ & $17.1 \pm 12.0$ & 0.536 \\
\hline Protein $(\mathrm{g} / \mathrm{dl})$ & $6.3 \pm 0.9$ & $6.0 \pm 1.0$ & 0.005 \\
\hline Albumin (g/dl) & $3.2 \pm 0.7$ & $3.0 \pm 0.6$ & 0.107 \\
\hline Creatinine (mg/dl) & $0.4 \pm 0.3$ & $0.6 \pm 1.0$ & 0.146 \\
\hline Prothrombin time (INR) & $1.9 \pm 1.2$ & $2.0 \pm 1.1$ & 0.547 \\
\hline aPTT (sec) & $47.9 \pm 27.7$ & $49.9 \pm 28.4$ & 0.655 \\
\hline C-reactive protein (mg/l) & $1.0 \pm 1.4$ & $1.5 \pm 1.8$ & 0.025 \\
\hline \multicolumn{4}{|l|}{ Intraoperative variables } \\
\hline $\begin{array}{l}\text { Packed red blood cell use } \\
(\mathrm{U} / \mathrm{kg})\end{array}$ & $0.1 \pm 0.1$ & $0.7 \pm 0.7$ & $<0.001$ \\
\hline Cryoprecipitate use (U/kg) & $0.02 \pm 0.1$ & $0.10 \pm 0.1$ & $<0.001$ \\
\hline $\begin{array}{l}\text { Fresh frozen plasma use } \\
(\mathrm{U} / \mathrm{kg})\end{array}$ & $0.1 \pm 0.2$ & $0.3 \pm 0.4$ & $<0.001$ \\
\hline $\begin{array}{l}\text { Platelet concentrate use } \\
(\mathrm{U} / \mathrm{kg})\end{array}$ & $0.02 \pm 0.1$ & $0.10 \pm 0.1$ & $<0.001$ \\
\hline Crystalloid use (ml/kg) & $150.0 \pm 151.6$ & $183.2 \pm 110.1$ & 0.047 \\
\hline Colloid use (ml/kg) & $47.4 \pm 45.4$ & $83.4 \pm 65.9$ & $<0.001$ \\
\hline Operation time (min) & $664.8 \pm 174.5$ & $700.7 \pm 164.8$ & 0.097 \\
\hline
\end{tabular}

Data are the mean \pm standard deviation. WBC, white blood cell; INR, international normalized ratio; aPTT, activated partial thromboplastin time.

\section{Discussion}

In the present study, we found that the risk factors for intraoperative massive transfusion in pediatric LT were high WBC count, low platelet count, and cadaveric donor. We also found that early graft failure tended to be higher in the massive transfusion group than in the no-massive transfusion group.

Massive transfusion may be associated with serious complications such as hypothermia, electrolyte abnormalities, immunologic complications, coagulopathy, transfusion reactions, and postoperative mortality [14, 18, 19]. Although the factors predicting blood loss and transfusion during LT have been previously evaluated, those studies primarily included adult patients [13, 20-24]. Moreover, the factors influencing blood transfusion in pediatric LT were evaluated under preoperative conditions, with varying anatomical and surgical factors [4, 5]. However, the results have not been consistent, due to the differences in the preoperative status, surgical techniques [22], massive transfusion definitions [5], and transfusion triggers between studies. In our present study, we followed a commonly used definition of massive transfusion in children [14] and divided the cases into the massive blood transfusion and no-massive blood transfusion groups. Furthermore, we believe that our current results are reliable because the data were collected from a single institution that had highly experienced surgical and anesthetic teams [25-27].
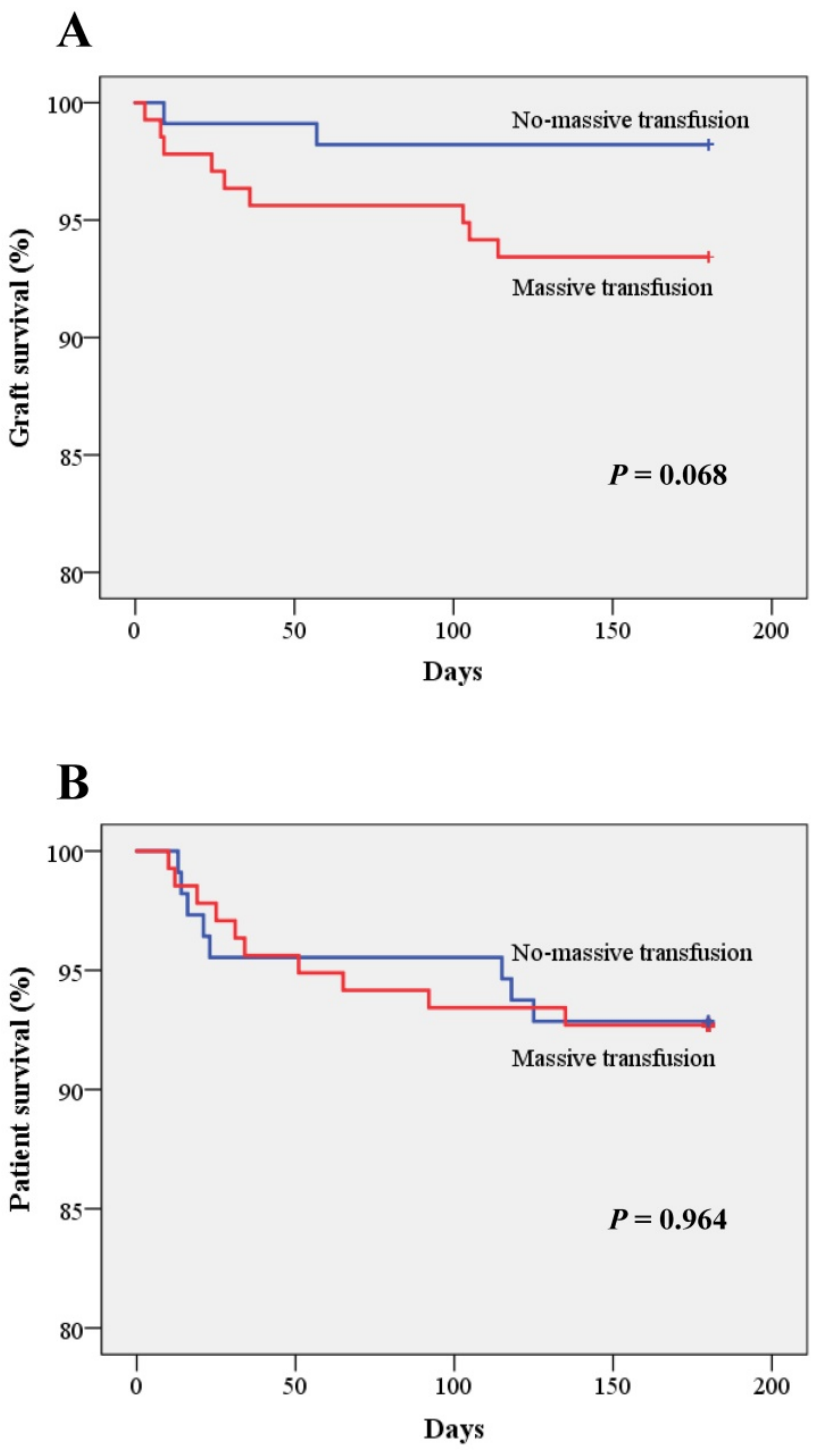

Figure 3. Kaplan-Meier curves of graft survival (A) and patient survival (B) within 6 months of the pediatric liver transplantation. The blue solid line indicates patient or graft survival in the no-massive transfusion group. The red solid line indicates patient or graft survival in the massive transfusion group.

In our present series, a high WBC count was a unique factor that predicted intraoperative massive transfusion during pediatric LT. Previous studies have indicated that bacterial infections are common in patients with upper gastrointestinal hemorrhage [28-30], possibly because of preoperative invasive procedures, bacterial translocation in the intestine, and defects in the scavenging system $[29,31]$. Bernard et al. showed that bacterial infection is not only an independent factor of bleeding in liver dysfunction patients, but is also an important prognostic factor for mortality [30]. The relationship between bleeding and bacterial infection in these studies supports our 
finding that leukocytosis can produce massive bleeding in patients with liver dysfunction. Moreover, peritoneal adhesion is inevitable after trans-peritoneal surgery. Children with biliary atresia, recurrent peritonitis, or cholangitis, which cause inevitable peritoneal adhesion, are commonly encountered, particularly among those with hepatoportoenterostomy. Adhesiolysis during LT can lead to increased blood loss [10], which may then contribute to massive transfusion in patients with coagulopathy or hemodynamic instability. Moreover, bacterial infection can lead to failure of bleeding control in the esophageal varix [32]. Our study suggests that massive transfusion during LT occurs more easily in children who are susceptible to bacterial infection and recurrent inflammation of the abdominal cavity.

Table 3. Univariate analysis of the risk factors for a massive transfusion during pediatric liver transplantation.

\begin{tabular}{|c|c|c|c|}
\hline Variables & Odds ratio & $\begin{array}{l}95 \% \text { confidence } \\
\text { interval }\end{array}$ & $P$ value \\
\hline \multicolumn{4}{|l|}{ Sex } \\
\hline Female & 1.000 & & \\
\hline Male & 0.596 & $0.360-0.986$ & 0.044 \\
\hline Age & 0.975 & $0.927-1.026$ & 0.336 \\
\hline Weight & 0.996 & $0.982-1.011$ & 0.592 \\
\hline Height & 0.995 & $0.988-1.003$ & 0.220 \\
\hline \multicolumn{4}{|l|}{ Primary diagnosis } \\
\hline Biliary atresia & 1.000 & & \\
\hline Wilson's disease & 1.843 & $0.612-5.555$ & 0.277 \\
\hline Other diseases ${ }^{a}$ & 0.797 & $0.475-1.337$ & 0.389 \\
\hline \multicolumn{4}{|l|}{ Donor type } \\
\hline Living donor & 1.000 & & \\
\hline Cadaveric donor & 3.514 & $1.463-8.439$ & 0.005 \\
\hline \multicolumn{4}{|c|}{ Surgical technique for the donor } \\
\hline Left lateral segment & 1.000 & & \\
\hline Left lobe & 0.529 & $0.302-0.929$ & 0.027 \\
\hline Other techniques ${ }^{b}$ & 1.634 & $0.772-3.455$ & 0.199 \\
\hline \multicolumn{4}{|l|}{ Elective/Emergent LT } \\
\hline Elective & 1.000 & & \\
\hline Emergent & 1.596 & $0.886-2.873$ & 0.119 \\
\hline Re-LT & 2.831 & $0.896-8.939$ & 0.076 \\
\hline Ascites & 1.700 & $1.027-2.813$ & 0.039 \\
\hline Chronic kidney disease & 4.802 & $1.042-22.134$ & 0.044 \\
\hline Esophageal varix & 0.802 & $0.447-1.441$ & 0.461 \\
\hline Peritonitis & 1.210 & $0.668-2.194$ & 0.529 \\
\hline Previous abdominal surgery & 1.206 & $0.731-1.988$ & 0.464 \\
\hline Portal vein thrombosis & 0.595 & $0.200-1.770$ & 0.351 \\
\hline WBC & 1.082 & $1.022-1.145$ & 0.006 \\
\hline Hemoglobin & 0.833 & $0.722-0.960$ & 0.012 \\
\hline Platelet & 0.996 & $0.993-0.999$ & 0.007 \\
\hline Total bilirubin & 1.007 & $0.985-1.029$ & 0.534 \\
\hline Albumin & 0.718 & $0.479-1.076$ & 0.108 \\
\hline Creatinine & 1.358 & $0.874-2.110$ & 0.173 \\
\hline Prothrombin time & 1.070 & $0.859-1.334$ & 0.546 \\
\hline Operation time & 1.001 & $1.000-1.003$ & 0.101 \\
\hline
\end{tabular}

LT, liver transplantation; WBC, white blood cell. aOther diseases included hepatoblastoma, viral hepatitis, toxic hepatitis, liver cirrhosis, acute liver failure, glycogen storage disease, and metabolic disease. bOther techniques included right lobe, dual left lobe, and whole liver.
Table 4. Multivariate analysis of the risk factors for a massive transfusion during pediatric liver transplantation.

\begin{tabular}{|c|c|c|c|c|c|}
\hline Variables & $\begin{array}{l}\text { Regression } \\
\text { coefficient }\end{array}$ & Wald & $\begin{array}{l}\text { Odds } \\
\text { ratio }\end{array}$ & $\begin{array}{l}95 \% \text { confidence } \\
\text { interval }\end{array}$ & $\begin{array}{l}P \\
\text { value }\end{array}$ \\
\hline WBC & 0.159 & 17.1 & 1.172 & $1.087-1.264$ & $<0.001$ \\
\hline Platelet & -0.007 & 15.7 & 0.993 & $0.989-0.996$ & $<0.001$ \\
\hline \multicolumn{6}{|l|}{ Donor type } \\
\hline Living donor & & & 1.000 & & \\
\hline Cadaveric donor & 1.503 & 10.5 & 4.496 & $1.809-11.173$ & 0.001 \\
\hline
\end{tabular}

WBC, white blood cell.

Our finding of the association between low platelet count and massive transfusion is consistent with that observed in previous studies $[22,33]$. Deakin et al. demonstrated that low platelet count was the best predictor of massive transfusion. Similarly, the intraoperative transfusion requirement during LT was strongly associated with lower platelet count [33]. Marino et al. showed that patients who could not maintain normal platelet levels, despite the preoperative correction of platelet counts, were likely to have a high level of blood usage [34]. Importantly, a lower platelet count is associated with impaired coagulation function, which can lead to bleeding and blood transfusion during pediatric LT.

We found that the incidence of massive transfusion was higher in patients who underwent cadaveric donor LT than in those who underwent living-donor LT [35]. Fasco et al. reported that patients who underwent living-donor LT required $66 \%$ fewer total blood products, as compared to those who underwent cadaveric donor LT, and that patients in the living-donor LT group had milder disease and more preserved coagulation function than those in the cadaveric donor LT group. In our present study, cadaveric donor LT was selected if the patient was undergoing an emergent operation or had fulminant hepatic failure, and if the patient did not have a living donor. However, some other studies have indicated conflicting results [7, 36, 37]. Pirate et al. did not observe a significant difference in blood transfusion between cadaveric donor LT and living-donor LT. The reasons for such discrepancies may be due to the differences in the preoperative conditions of patients, blood transfusion triggers, and inclusion criteria for LT recipients.

In our present analysis, the incidence of early graft failure tended to be higher in the massive transfusion group than in the no-massive transfusion group (6.6\% vs. $1.8 \%, P=0.068)$. Previous studies showed that massive transfusion was commonly associated with a wide range of complications, such as transfusion reactions to liver graft, systemic immunological deteriorations, metabolic deteriorations, and coagulopathy [14], and indicated 
the need for careful monitoring and strategy to reduce large blood loss and subsequent massive transfusion. Moreover, studies have reported a wide variation in graft survival $[38,39]$. Hence, further study is needed to clarify the association between massive transfusion and graft failure in pediatric LT.

There is a possibility of selection bias due to the retrospective nature of the present study. As patients were not enrolled according to predefined criteria, the wide range of age, weight, height, or disease entity may affect our results. However, we assessed almost all the possible variables associated with massive transfusion. Hence, there is minimal possibility of bias in the selection of study patients.

In conclusion, we have found that high WBC count, low platelet count, and cadaveric donor are significant factors for predicting massive transfusion during pediatric LT. This result may offer valuable information on perioperative transfusion management in pediatric recipients who have a high risk of massive bleeding during LT.

\section{Abbreviations}

LT, liver transplantation; WBC, white blood cell.

\section{Conflict of interests}

The authors have no funding or other conflicts of interest to disclose.

\section{References}

1. Starzl TE, Koep LJ, Schroter GP, Halgrimson CG, Porter KA, Weil R, 3rd. Liver replacement for pediatric patients. Pediatrics. 1979; 63: 825-9.

2. Devictor D, Tissieres P. Pediatric liver transplantation: where do we stand? Where we are going to? Expert Review of Gastroenterology \& Hepatology. 2013; 7: 629-41.

3. McDiarmid SV, Anand R, Martz K, Millis MJ, Mazariegos G. A multivariate analysis of pre-, peri-, and post-transplant factors affecting outcome after pediatric liver transplantation. Ann Surg. 2011; 254: 145-54.

4. Lichtor JL, Emond J, Chung MR, Thistlethwaite JR, Broelsch CE. Pediatric orthotopic liver transplantation: multifactorial predictions of blood loss. Anesthesiology. 1988; 68: 607-11.

5. Ozier YM, Le Cam B, Chatellier G, Eyraud D, Soubrane O, Houssin D, et al. Intraoperative blood loss in pediatric liver transplantation: analysis of preoperative risk factors. Anesth Analg. 1995; 81: 1142-7.

6. Barcelona SL, Thompson AA, Cote CJ. Intraoperative pediatric blood transfusion therapy: a review of common issues. Part I: hematologic and physiologic differences from adults; metabolic and infectious risks. Paediatr Anaesth. 2005; 15: 716-26.

7. Ulukaya S, Acar L, Ayanoglu HO. Transfusion requirements during cadaveric and living donor pediatric liver transplantation. Pediatr Transplant. 2005; 9: 332-7.

8. Barcelona SL, Thompson AA, Cote CJ. Intraoperative pediatric blood transfusion therapy: a review of common issues. Part II: transfusion therapy, special considerations, and reduction of allogenic blood transfusions. Paediatr Anaesth. 2005; 15: 814-30.

9. Kasai M, Suzuki S. A new operation for non-correctable biliary atresia: hepatic portoenterostomy Shujutsu. 1959; 13: 733-9.

10. Liakakos T, Thomakos N, Fine PM, Dervenis C, Young RL. Peritoneal Adhesions: Etiology, Pathophysiology, and Clinical Significance. Digestive Surgery. 2001; 18: 260-73

11. Hendriks HG, van der Meer J, de Wolf JT, Peeters PM, Porte RJ, de Jong K, et al. Intraoperative blood transfusion requirement is the main determinant of early surgical re-intervention after orthotopic liver transplantation. Transpl Int. 2005; 17: 673-9.

12. Cacciarelli TV, Keeffe EB, Moore DH, Burns W, Busque S, Concepcion W, et al. Effect of intraoperative blood transfusion on patient outcome in hepatic transplantation. Arch Surg. 1999; 134: 25-9.
13. Ramos E, Dalmau A, Sabate A, Lama C, Llado L, Figueras J, et al. Intraoperative red blood cell transfusion in liver transplantation: influence on patient outcome, prediction of requirements, and measures to reduce them. Liver Transpl. 2003; 9: 1320-7.

14. Diab YA, Wong EC, Luban NL. Massive transfusion in children and neonates. Br J Haematol. 2013; 161: 15-26.

15. Ben-Ari Z, Weiss-Schmilovitz H, Sulkes J, Brown M, Bar-Nathan N, Shaharabani E, et al. Serum cholestasis markers as predictors of early outcome after liver transplantation. Clin Transplant. 2004; 18: 130-6.

16. Olthoff KM, Kulik L, Samstein B, Kaminski M, Abecassis M, Emond J, et al. Validation of a current definition of early allograft dysfunction in liver transplant recipients and analysis of risk factors. Liver Transpl. 2010; 16: 943-9.

17. Nanashima A, Pillay P, Verran DJ, Painter D, Nakasuji M, Crawford M, et al. Analysis of initial poor graft function after orthotopic liver transplantation: experience of an australian single liver transplantation center. Transplant Proc. 2002; 34: 1231-5.

18. Shaw BW, Jr., Wood RP, Gordon RD, Iwatsuki S, Gillquist WP, Starzl TE. Influence of selected patient variables and operative blood loss on six-month survival following liver transplantation. Semin Liver Dis. 1985; 5: 385-93.

19. Brems JJ, Hiatt JR, Colonna JO, 2nd, el-Khoury G, Quinones WJ, Ramming KP, et al. Variables influencing the outcome following orthotopic liver transplantation. Arch Surg. 1987; 122: 1109-11.

20. Araujo T, Cordeiro A, Proenca P, Perdigoto R, Martins A, Barroso E. Predictive variables affecting transfusion requirements in orthotopic liver transplantation. Transplant Proc. 2010; 42: 1758-9.

21. Xia VW, Fond A, Du B. Ascites, but not hyponatremia, is associated with high intraoperative transfusion and vasopressor requirements during liver transplantation. Transplant Proc. 2006; 38: 1398-9.

22. Deakin M, Gunson BK, Dunn JA, McMaster P, Tisone G, Warwick J, et al. Factors influencing blood transfusion during adult liver transplantation. Ann R Coll Surg Engl. 1993; 75: 339-44.

23. Xia VW, Du B, Braunfeld M, Neelakanta G, Hu KQ, Nourmand H, et al. Preoperative characteristics and intraoperative transfusion and vasopressor requirements in patients with low vs. high MELD scores. Liver Transpl. 2006; 12: $614-20$.

24. Pandey CK, Singh A, Kajal K, Dhankhar M, Tandon M, Pandey VK, et al. Intraoperative blood loss in orthotopic liver transplantation: The predictive factors. World J Gastrointest Surg. 2015; 7: 86-93.

25. Choi S-S, Cho S-S, Kim S-H, Jun I-G, Hwang G-S, Kim Y-K. Factors Associated With Blood Transfusion in Donor Hepatectomy: Results from 2344 Donors at a Large Single Center. Transplantation. 2013; 96: 1000-7.

26. Choi S-S, Kim S-H, Kim Y-K. Fluid management in living donor hepatectomy: Recent issues and perspectives. World Journal of Gastroenterology. 2015; 21: 12757-66.

27. Lee SG. A complete treatment of adult living donor liver transplantation: a review of surgical technique and current challenges to expand indication of patients. Am J Transplant. 2015; 15: 17-38.

28. Soriano G, Guarner C, Tomas A, Villanueva C, Torras X, Gonzalez D, et al. Norfloxacin prevents bacterial infection in cirrhotics with gastrointestinal hemorrhage. Gastroenterology. 1992; 103: 1267-72.

29. Blaise M, Pateron D, Trinchet JC, Levacher S, Beaugrand M, Pourriat JL. Systemic antibiotic therapy prevents bacterial infection in cirrhotic patients with gastrointestinal hemorrhage. Hepatology. 1994; 20: 34-8.

30. Bernard B, Cadranel JF, Valla D, Escolano S, Jarlier V, Opolon P. Prognostic significance of bacterial infection in bleeding cirrhotic patients: a prospective study. Gastroenterology. 1995; 108: 1828-34.

31. Rimola A, Soto R, Bory F, Arroyo V, Piera C, Rodes J. Reticuloendothelial system phagocytic activity in cirrhosis and its relation to bacterial infections and prognosis. Hepatology. 1984; 4: 53-8.

32. Goulis J, Armonis A, Patch D, Sabin C, Greenslade L, Burroughs AK. Bacterial infection is independently associated with failure to control bleeding in cirrhotic patients with gastrointestinal hemorrhage. Hepatology. 1998; 27: 1207-12.

33. Cywinski JB, Alster JM, Miller C, Vogt DP, Parker BM. Prediction of intraoperative transfusion requirements during orthotopic liver transplantation and the influence on postoperative patient survival. Anesth Analg. 2014; 118: 428-37.

34. Marino IR, Weber T, Esquivel CO, Kang YG, Starzl TE, Duquesnoy RJ. Intraoperative blood transfusion requirements and deficient hemostasis in highly alloimmunized patients undergoing liver transplantation. Transplant Proc. 1988; 20: 1087-9.

35. Frasco PE, Poterack KA, Hentz JG, Mulligan DC. A comparison of transfusion requirements between living donation and cadaveric donation liver transplantation: relationship to model of end-stage liver disease score and baseline coagulation status. Anesth Analg. 2005; 101: 30-7.

36. Pirat A, Sargin D, Torgay A, Arslan G. Identification of preoperative predictors of intraoperative blood transfusion requirement in orthotopic liver transplantation. Transplant Proc. 2002; 34: 2153-5.

37. Tully M, Burkle C, Plevak D. Pilot study to determine blood and blood component transfusion differences between patients receiving orthotopic cadaveric versus living related donor liver transplant. Liver Transpl. 2002; 8: C1.

38. González FX, Rimola A, Grande L, Antolin M, Garcia-Valdecasas JC, Fuster J, et al. Predictive factors of early postoperative graft function in human liver transplantation. Hepatology. 1994; 20: 565-73. 
39. Ploeg RJ, D'Alessandro AM, Knechtle SJ, Stegall MD, Pirsch JD, Hoffmann RM, et al. Malfunction of the liver after transplantation: an analysis of potential risk factors. Transplant Proc. 1993; 25: 1659-61. 